\title{
Quantitative TOF-SIMS Analysis of Oligomeric Degradation Products at the Surface of Biodegradable Poly( $\alpha$-Hydroxy Acid)s
}

Joo-Woon Lee and Joseph A. Gardella, Jr.

Department of Chemistry, State University of New York at Buffalo, Buffalo, New York, USA

This paper reports the development of a new method for quantification of the hydrolytic surface degradation kinetics of biodegradable poly( $\alpha$-hydroxy acid)s using time-of-flight secondary ion mass spectrometry (TOF-SIMS). We report results from static SIMS spectra of a series of poly( $\alpha$-hydroxy acid)s including poly(glycolic acid), poly( ${ }_{\mathrm{L}}$-lactic acid), and random poly $(\mathrm{D}, \mathrm{L}-$-lactic acid-co-glycolic acid) hydrolyzed in various buffer systems. The distribution of the most intense peak intensities of ions generated in high mass range of the spectrum reflects the intact degradation products (oligomeric hydrolysis products) of each biodegradable polymer. First, a detailed analysis of the oligomeric ions is given based on rearrangement of the intact hydrolysis products. The pattern of ions can distinguish both degradation-generated intact oligomers and their fragment ion peaks with a variety of combinations of each repeat unit. Then, the integration and summation of the area of all ion peaks with the same number of repeat units is proposed as a measurement that provides a more accurate MW average than the typically used method which counts only the most intense peak. The multiple ion summation method described in this paper would be practical in the improvement of quantitative TOF-SIMS studies as a better data reduction method, especially in the surface degradation kinetics of biodegradable polymers. (J Am Soc Mass Spectrom 2002, 13, 1108-1119) (c) 2002 American Society for Mass Spectrometry

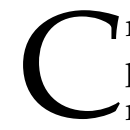
rucial properties such as adhesion and biocompatibility of biodegradable polymers in the biomedical applications for drug delivery devices and tissue engineering are governed by the molecular state at the topmost surface [1]. Time-of-flight secondary ion mass spectrometry (TOF-SIMS) [2-4] stands as a promising technique allowing quantitative polymer surface analysis for both the characterization of existing biodegradable polymer matrices and the design of new surfaces with well-controlled properties. This is because the secondary molecular ions that are emitted from the surface are very characteristic of the functional groups and the chemical structures present at the uppermost surface [5-8]. This information often complements another major surface technique, X-ray photoelectron spectroscopy (XPS), since XPS [2] generally provides only average surface chemical composition. TOF-SIMS has been now widely applied to the investigation of the surface molecular weights and end groups [6], surface

Published online August 19, 2002

Address reprint requests to Dr. J. A. Gardella, Jr., Department of Chemistry, State University of New York at Buffalo, 470 Natural Sciences Complex, Buffalo, NY 14260-3000, USA. E-mail: gardella@acsu.buffalo.edu crystallization [9], surface specific interactions [10], polymer surface modifications [11], surface contaminants [12], additives in a polymer [13], and detailed structural characterization [14, 15] and quantitative analysis [16-20] of polymers. Most TOF-SIMS spectra of polymers have been obtained in the mass range $\mathrm{m} / \mathrm{z}$ $<10,000[5,18-20]$.

Two main processes are observed in the TOF-SIMS spectra of polymers; these are the fragmentation of polymer chains and the desorption of intact oligomers. Fragmentation under ion bombardment in ultra-high vacuum (UHV) environment generates distinct fragmentation patterns that are unique to a given polymer. From the fragmentation patterns the mass of the repeat unit, terminal groups, side groups, and functional groups in a repeat unit can be determined [14, 15]. Desorption of intact oligomers provides a direct measure of molecular weight distribution (MWD) from which a molecular weight average can be evaluated. According to the recent reports $[21,22]$ on the comparison of mass spectrometric techniques, TOF-SIMS produced a result similar to electrospray ionization (ESI) and fast atom bombardment (FAB). They consistently showed lower MW averages compared with gel permeation chromatography (GPC)-deduced results, whereas 
matrix-assisted laser desorption/ionization (MALDI) and field desorption (FD) results are higher.

In the quantitative degradation studies of biodegradable polymers, a conventional bulk characterization technique like GPC [23-26] has been widely employed for the determination of decrease in MW average of polymer matrices retrieved at various time intervals. However, the bulk properties do not always represent the surface characteristics of degraded biodegradable polymer matrices and do not provide any information about chemical structure and MWD of degradation products, degradation reaction mechanism, and chemical structural change that may occur at the surface during degradation process.

The accurate measurement of MWD of degradation products is essential and important not only to establish degradation kinetics of biodegradable polymers, but also to understand the physicochemical surface interactions between absorbable biomedical devices and biological environments. TOF-SIMS results from our laboratory [27-29] have identified and characterized the MWD of hydrolytic degradation reaction products adsorbed at the surface of various biodegradable polymers, demonstrated the generality of such reactions among seven biodegradable polymers [28] and quantified the kinetics of degradation of PGA [29]. In our previous studies, however, only a series of the most intense molecular ion peaks as intact degradation reaction products were analyzed in a fixed mass range $m / z=600 \sim 2000$ for the quantification of MWD of degradation products.

In the present report, hydrolytic degradation of $\operatorname{poly}(\alpha$-hydroxy acid)s [e.g., poly(glycolic acid) (PGA), poly(L-lactic acid) (PLLA), and poly(lactic-co-glycolic acid) (PLGA)] is investigated as a function of hydrolysis time in various $\mathrm{pH}$ buffer media. Periodic peak patterns of intact hydrolysis products and fragments and corresponding chemical structures are systematically identified. Discussed is how the peak "families" are generated during hydrolytic degradation process and/or TOFSIMS experiment. The intensities of these oligomeric ion peaks with the same repeat number (n) are then integrated together as the total intensity for the degradation product with the same $\mathrm{n}$. We have considered this practice of multiple ion summation to improve the quality of data for direct determination of MW average. This is compared with the previous single ion count method that only analyzes the most intense molecular ion peak for the representative intensity. The multiple ion summation method is shown to provide a better quantification method for the accurate MW determination from the MWD of degradation products adsorbed at the surface of PGA matrices. (Details of hydrolytic PGA degradation studies are reported in a separate paper [30] with the emphasis in quantitative surface versus bulk characterization at the initial stage of bulk erosion process.)
Table 1. Chemical composition of saline buffer solutions used in hydrolysis treatment

\begin{tabular}{llr}
\hline Saline solution & \multicolumn{2}{c}{ Composition } \\
\hline \hline $\begin{array}{l}\text { Physiological Buffer: ISOTON II } \\
\text { (pH 7.4) }\end{array}$ & $\mathrm{NaCl}$ & $7.93 \mathrm{~g} / \mathrm{L}$ \\
& $\mathrm{Na}_{2} \mathrm{HPO}_{4}$ & $1.95 \mathrm{~g} / \mathrm{L}$ \\
& $\mathrm{KCl}$ & $0.40 \mathrm{~g} / \mathrm{L}$ \\
& $\mathrm{Na}_{2} \mathrm{EDTA} \cdot 2 \mathrm{H}_{2} \mathrm{O}$ & $0.38 \mathrm{~g} / \mathrm{L}$ \\
& $\mathrm{NaF}$ & $1.30 \mathrm{~g} / \mathrm{L}$ \\
& $\mathrm{NaH}_{2} \mathrm{PO}_{4}$ & $0.19 \mathrm{~g} / \mathrm{L}$ \\
Potassium Carbonate Buffer & $\mathrm{K}_{2} \mathrm{CO}_{3}$ & \\
(pH 10.0) & $\mathrm{KOH}$ & $\mathrm{NA}$ \\
& $\mathrm{K}_{2} \mathrm{~B}_{4} \mathrm{O}_{7} \cdot 5 \mathrm{H}_{2} \mathrm{O}$ & \\
& $\mathrm{Na}_{2} \mathrm{EDTA}_{2} \cdot 2 \mathrm{H}_{2} \mathrm{O}$ & \\
Sodium Carbonate Buffer & $\mathrm{Na}_{2} \mathrm{CO}_{3}$ & $0.025 \mathrm{M}$ \\
(pH 10.0) & $\mathrm{NaHCO}_{3}$ & $0.025 \mathrm{M}$ \\
\hline
\end{tabular}

\section{Experimental}

\section{Materials and Specimen Preparation}

High molecular weight PGA (mol. wt.: >300,000) was supplied by Dr. Peter Jarrett of Davis \& Geck Division of American Cyanamid Company (One Casper St. Danbury, CT). PLLA (mol. wt.: 100,000) was purchased from Polysciences, Inc. (Warrington, PA), and PLGA (50:50, mol. wt.: 50,000 75,000) was from Sigma Chemical Co. (St. Louis, MO). A physiological electrolyte buffer solution, ISOTON II (pH 7.4 at $\left.25^{\circ} \mathrm{C}\right)$, was purchased from Coulter Diagnostics (a division of Coulter Electronics, Inc., Hialeah, FL). Potassium carbonate buffer solution $\left(\mathrm{pH} 10.0\right.$ at $25^{\circ} \mathrm{C}$ ) was purchased from Fischer Scientific (Fair Lawn, NJ) and sodium carbonate buffer ( $\mathrm{pH} 10.0$ at $25^{\circ} \mathrm{C}$ ) solution was prepared with buffer concentrates (DILUT-IT) purchased from T. J. Baker Inc. (Phillipsburg, NJ). The chemical composition of each buffer solution is listed in Table 1 . Reagent grade $n$-hexane (Fisher Scientific) was used for surface cleaning as received and HPLC grade chloroform (Aldrich) was used for the preparation of $\sim 2 \%(\mathrm{w} / \mathrm{vol}$ ) PLLA and PLGA solutions.

PGA plates were prepared by melt-cast to ca. $1 \mathrm{~mm}$ thick as described in previous papers [27-29] and transparent films [30] with thickness ca. $100 \mu \mathrm{m}$ were made from $1 \mathrm{~mm}$ plates in the same way. The reason to use melt-casting method is that PGA shows very low solubility in most common organic solvents with the exception being hexafluoroisopropanol. All PGA specimens were ultrasonically cleaned in $n$-hexane for $2 \mathrm{~min}$ before and after melt-cast each. PLLA and PLGA thin films were spin-coated onto $10 \times 10 \mathrm{~mm}$ glass plates at $2000 \mathrm{rpm}$ for $60 \mathrm{~s}$ using a Headway Research Inc. Model EC 101 spin-coater. In order to avoid specimen hydrolysis and contamination, exposure to atmospheric conditions was minimized if at all possible.

The hydrolytic degradation of all polymer specimens was carried out at $37.0 \pm 0.2^{\circ} \mathrm{C}$ in various $\mathrm{pH}$ saline buffer solutions to regulate the local autocatalytic effect $[31,32]$ of carboxylic acid end groups generated during 
hydrolysis treatment. Each specimen was immersed in a separate vial prefilled with $24 \mathrm{ml}$ of aqueous treatment solution and then reaction vials were placed in an isothermal water bath for the predetermined time. All specimens after the hydrolysis treatment were vacuumdried at ambient temperature at least for $24 \mathrm{~h}$ before being analyzed.

\section{TOF-SIMS Instrument}

TOF-SIMS analysis was performed using a Physical Electronics 7200 time-of-flight secondary ion mass spectrometer equipped with a $\mathrm{Cs}^{+}$ion gun, a reflectron assembly, and a channel plate detector. The primary ion gun was operated at $8 \mathrm{keV}$ for all experiments. The static mode was used in all acquisitions with primary ion current of $0.3 \mathrm{pA}$. The pulse width of primary ion current was $1.0 \mathrm{~ns}$. The extractor was operated in the positive ion mode. The total ion dosage in each spectral acquisition was no more than $1 \times 10^{11} \mathrm{ion} / \mathrm{cm}^{2}$. An electron neutralizer was operated during all spectral acquisitions in pulsed mode at low electron energy with a target current under $1 \mu \mathrm{A}$ for charge compensation. A time resolution of 1.25 ns per step was used for good signal-to-noise ratio at high $\mathrm{m} / \mathrm{z}$ range. The pressure of the main chamber was kept between $10^{-8}$ and $10^{-10}$ torr for each analysis. Each specimen was analyzed a minimum of three times.

\section{Measurement of MWD}

The spectra were analyzed using Physical Electronics TOFPak (Version 2.0A) software, and the mass and area of each ion in the spectrum were individually recorded. Various families of ions can be distinguished based on each repeat unit and chemical structure of a series of poly( $\alpha$-hydroxy acid)s. These databases were subsequently analyzed using the conventional statistical averaging definitions for the number $\left(M_{n}\right)$ and weight $\left(M_{\mathrm{w}}\right)$ average molecular weights, and the polydispersity index (PDI) built in Googly software [33]:

$$
\begin{aligned}
& M_{\mathrm{n}}=\Sigma N_{\mathrm{i}} M_{\mathrm{i}} / \Sigma N_{\mathrm{i}} \\
& M_{\mathrm{w}}=\Sigma N_{\mathrm{i}} M_{\mathrm{i}}^{2} / \Sigma N_{\mathrm{i}} M_{\mathrm{i}} \\
& \mathrm{PDI}=M_{\mathrm{w}} / M_{\mathrm{n}}
\end{aligned}
$$

where $M_{\mathrm{i}}$ is the mass of a particular species adjusted for its structure (i.e., if the $[\mathrm{M}+\mathrm{Na}]^{+}$family of ions was used, then the mass of $\mathrm{Na}$ was subtracted) and $N_{\mathrm{i}}$ is the area of that peak.

\section{Hydrolytic Degradation Kinetics}

The hydrolytic degradation of a series of $\operatorname{poly}(\alpha-$ hydroxy acid)s involves hydrolytic chain scissions of ester bond linkages in the polymer backbone by nucleo- philic attack of water molecules to form alcohol and carboxylic acid end groups. Hence, the hydrolytic degradation rate in non-catalytic system is proportional to water and ester concentrations at the solid matrix/ surrounding aqueous buffer interface. It can be expressed to a pseudo first-order reaction $[25,29]$ as follows:

$$
\ln [(\mathrm{DP}-1) / \mathrm{DP}]=-k t+\ln \left[\left(\mathrm{DP}_{0}-1\right) / \mathrm{DP}_{0}\right]
$$

where $k$ presents the rate constant for hydrolytic degradation, and DP and $\mathrm{DP}_{0}$ are the degrees of polymerization at times $t$ and zero, respectively. The average DP at time $t$ is defined as the average number of repeat unit in the degradation products of each poly $(\alpha$-hydroxy acid):

$$
\mathrm{DP}=\left(M_{\mathrm{n}}-18\right) /(\text { Mass of Repeat Unit })
$$

where 18 is the mass of both end-groups.

\section{Results and Discussion}

Figure 1 shows the comparison of positive TOF-SIMS spectra of PGA specimens (Figure 1a) before and (Figure $1 b$ and c) after hydrolysis treatment in two different $\mathrm{pH}$ buffered solutions. In Figure 1a, the spectrum of an untreated $100 \mu \mathrm{m}$ film dopped with $\mathrm{NaCl}$, very little except a noisy background can be observed over the $\mathrm{m} / \mathrm{z}$ range from $600 \mathrm{D}$. The lack of signals at high mass is likely due to the strong entanglement of the long chain polymer molecules. Upon exposure to the treatment buffer solution, however, ion peaks are observed over the high mass range $(>600 \mathrm{~m} / \mathrm{z})$ of the spectra in Figure $1 \mathrm{~b}$ and $\mathrm{c}$. Previous work has been based on the distribution of peaks which reflect the intact oligomeric hydrolysis products of PGA. This general result [27-30] is due to low MW PGA oligomers that are produced at the surface as a result of the hydrolytic degradation. These degradation-generated oligomers are shorter and less entangled enough to readily desorb from the surface as secondary ions. In Figure $1 b$ obtained from a 100 $\mu \mathrm{m}$ film hydrolyzed in $\mathrm{pH} 7.4$ physiological buffer, ISOTON II, for $3 \mathrm{~h}$ at $37^{\circ} \mathrm{C}$, the most intense peaks are labeled with an asterisk (*). The spacing between consecutive peaks is equal to the repeat unit $\left(M_{\mathrm{PGA}}=58.01\right.$ D) of PGA. The asterisks $(*)$ are assigned to $\mathrm{Na}^{+}-$ cationized PGA oligomer ions, $\left[\mathrm{nM}_{\mathrm{PGA}}+\mathrm{H}_{2} \mathrm{O}+\mathrm{Na}\right]^{+}$ with $\mathrm{n}=10 \sim 33$, where $\mathrm{Na}^{+}$comes from the buffer treatment solution and participates in the ionization process as an ionization assisting agent. Figure 1c is obtained from $1 \mathrm{~mm}$ plates hydrolyzed in $\mathrm{pH} 10.0$ potassium carbonate buffer for $4 \mathrm{~h}$ at $37^{\circ} \mathrm{C}$. This is an example to demonstrate that the formation of secondary molecular ions from intact degradation products is dependent on the chemical compositions in a buffer used. As expected from the name of a saline buffer solution of Table 1 , the concentration of sodium $\left(\left[\mathrm{Na}^{+}\right]\right)$ 

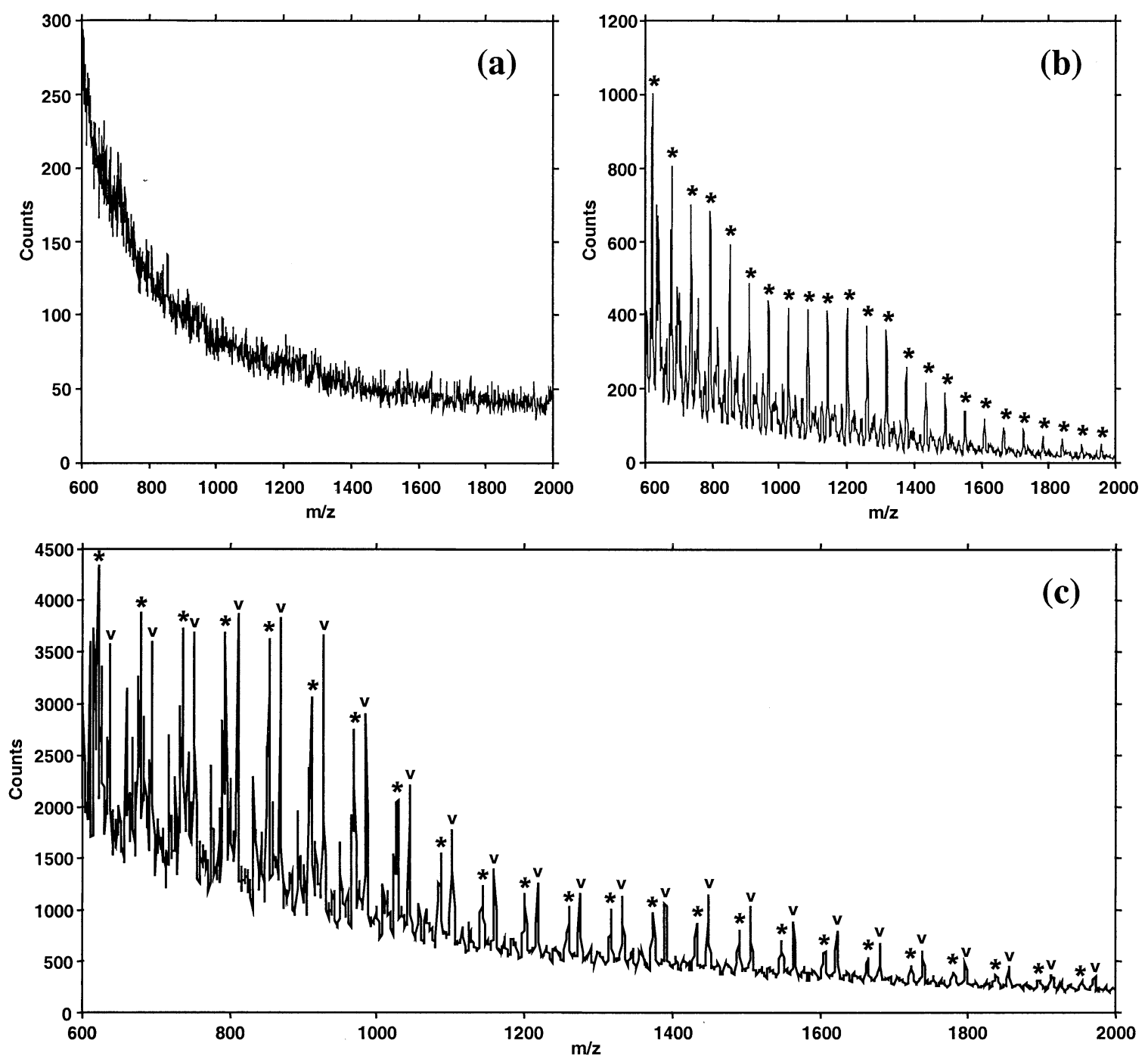

Figure 1. Comparison of positive survey TOF-SIMS spectra of PGA samples (a) before and (b) after hydrolysis treatment for $3 \mathrm{~h}$ in $\mathrm{pH} 7.4$ physiological buffer, ISOTON II, and (c) for $4 \mathrm{~h}$ in $\mathrm{pH} 10.0$ potassium carbonate buffer at $37^{\circ} \mathrm{C}$. Over the mass range $\mathrm{m} / z=600$ the intense peaks are due to desorption of intact oligomeric degradation products cationized with $\mathrm{N}^{\mathrm{a}}\left(*:\left[\mathrm{nM}_{\mathrm{PGA}}+\mathrm{H}_{2} \mathrm{O}+\mathrm{Na}\right]^{+}\right)$ and with $\mathrm{K}^{+}\left(\mathrm{v}\right.$ : $\left[\mathrm{nM}_{\mathrm{PGA}}+\mathrm{H}_{2} \mathrm{O}+\mathrm{K}\right]^{+}$) depending on chemical composition of saline buffer media used.

in potassium carbonate buffer would be lower than that of potassium $\left(\left[\mathrm{K}^{+}\right]\right)$. However, double series ( $*$ : $\left[\mathrm{n} M_{\mathrm{PGA}}\right.$ $\left.+\mathrm{H}_{2} \mathrm{O}+\mathrm{Na}\right]^{+}$and v: $\left[\mathrm{nM}_{\mathrm{PGA}}+\mathrm{H}_{2} \mathrm{O}+\mathrm{K}\right]^{+}$) of major peak intensity distributions are observed for intact degradation products due to the competitive substrate effect of two alkali metals. Therefore, TOF-SIMS in Figure 1 demonstrates that the cationization of neutral molecules with alkali metals is dependent on the degree of chelating potential, efficiency, and relative concentration of the cations contained in external hydrolysis solutions.

During the hydrolysis treatment of $100 \mu \mathrm{m}$ PGA films in pH 7.4 ISOTON II buffer, an interesting phenomenon is observed at the initial stage. Comparing relative intensities of intact degradation product ions, the most intense series of peaks changes as the hydro- lysis time is increased. This is shown in Figure 2a. The most intense peaks at $1 \mathrm{~h}$ hydrolysis treatment are labeled with a cross $(+)$, which is $22 \mathrm{D}$ greater than $\mathrm{Na}^{+}$-cationized oligomer ion (*) with the same repeat number. This indicates that a carboxylic acid proton of each neutral degradation product is replaced with one $\mathrm{Na}^{+}$, from which the peaks labeled (+) can be assigned to $\mathrm{Na}^{+}$-cationized polyglycolate sodium salt ions, $\left[\mathrm{nM}_{\mathrm{PGA}}+\mathrm{OH}+2 \mathrm{Na}\right]^{+}$(refer to Table 2). As hydrolysis time is increased, however, the series of $\mathrm{Na}^{+}$-cationized oligomer ions $(*)$ becomes the more predominant peaks in the spectrum. Figure $2 b$ is an exemplary TOF-SIMS spectrum to show both series $(*$ and + ) of molecular ion distribution of intact degradation products adsorbed at the surface of $1 \mathrm{~mm}$ PGA plates from $4 \mathrm{~h}$ exposure in pH 7.4 ISOTON II buffer. It can be concluded that two 
(a)
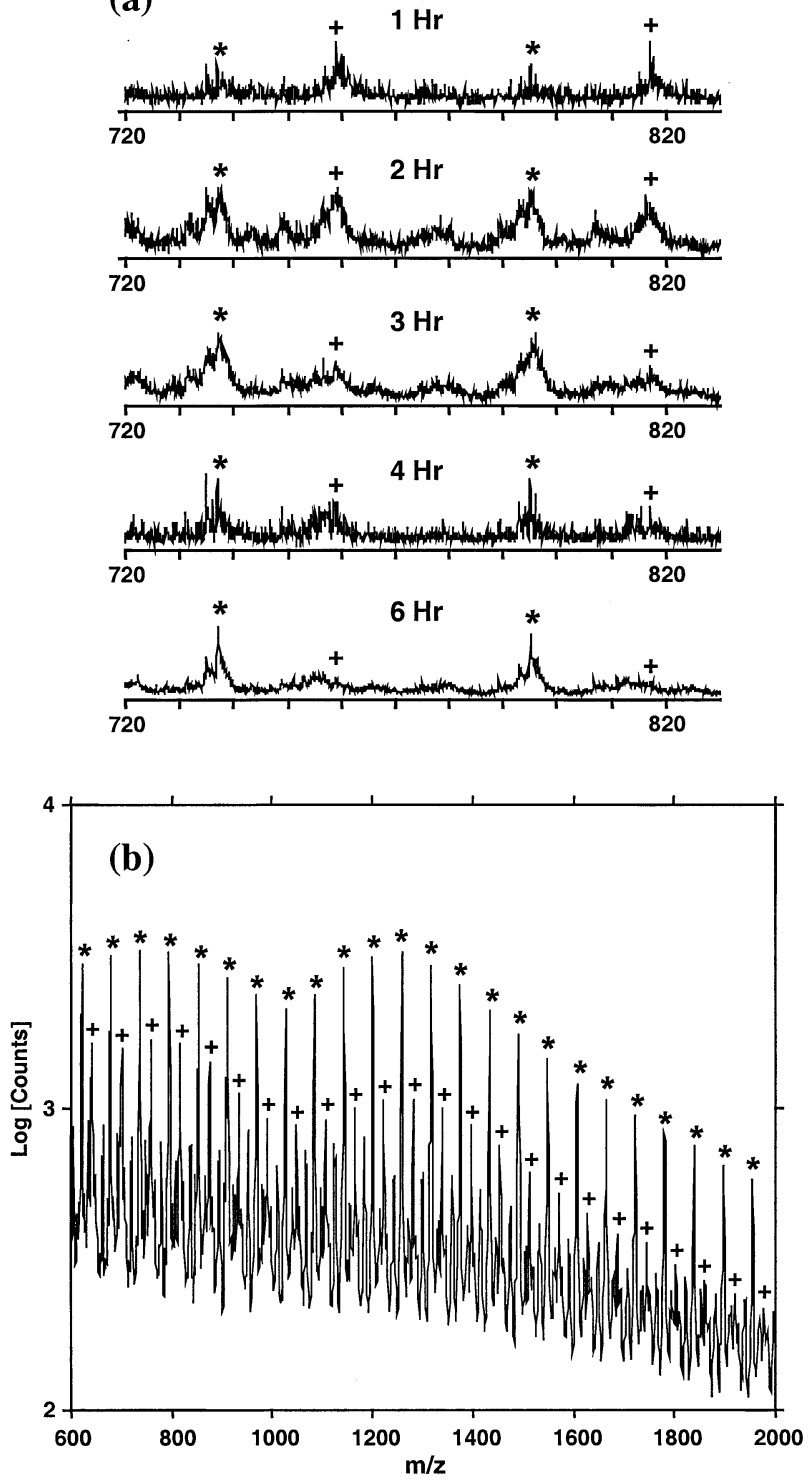

Figure 2. (a) Changes in relative intensity of two series (asterisk, cross) $(*,+)$ of intact oligomeric PGA degradation products observed from $1 \sim 6 \mathrm{~h}$ hydrolysis treatment of transparent $100 \mu \mathrm{m}$ films in pH 7.4 ISOTON II buffer at $37^{\circ} \mathrm{C}$ and (b) two series of the dual MWD of intact oligomeric PGA degradation products obtained from $4 \mathrm{~h}$ hydrolysis of $1 \mathrm{~mm}$ plates in $\mathrm{pH}$ 7.4 ISOTON II buffer at $37^{\circ} \mathrm{C}$, where cross mark $(+)$ represents $\left[\mathrm{n} M_{\mathrm{PGA}}+\mathrm{OH}+\right.$ $2 \mathrm{Na}]^{+}$. series $(*$ and +$)$ of molecular ions distribution have arisen from the desorption process of the intact oligomeric degradation products.

Besides the $\mathrm{Na}^{+}$-cationized polyglycolate sodium salt ion peaks $(+)$, four oligomeric ion peaks labeled $A$, $\mathrm{B}, \mathrm{C}$, and D are consistently observed within the spacing between consecutive most intense peaks $(*)$ in TOF-SIMS spectra of PGA hydrolyzed in various conditions (refer to Figure 3). These are likely due to the rearrangements from PGA degradation products with the greater repeat numbers during the SIMS ionization process. Details of each positive secondary ion formation from hydrolytic degradation products are shown in the $\mathrm{m} / \mathrm{z}$ range $1020 \sim 1150$ in TOF-SIMS spectrum of Figure 3 that is obtained from 4 h-hydrolysis treatment in pH 7.4 ISOTON II buffer. From the peak $\left(*_{18}\right)$ as an intact degradation product, (1) the peak labeled A is rearranged via neutral $\mathrm{H}_{2} \mathrm{O}$ and $\mathrm{CO}$ dissociation, (2) the peak labeled $\mathrm{B}$ results from the loss of $\mathrm{CO}_{2}$ of the carboxylic acid chain ends, (3) the peak labeled $\mathrm{C}$ is rearranged through the loss of $\mathrm{H}_{2} \mathrm{O}$, and (4) the peak labeled D is generated through $\mathrm{HOCH}_{2}$ radical fragmentation followed by $\mathrm{CO}_{2}$ dissociation from the peak $\left(*_{19}\right)$. Each mass formula and corresponding peak assignment are summarized in Table 2 for the oligomeric ion peak family $\left(\mathrm{A}, \mathrm{B},+_{17}, \mathrm{C}\right.$, and $\left.\mathrm{D}\right)$ observed within a consecutive two most intense peaks $\left(*_{17}\right.$ and $\left.*_{18}\right)$. In order to confirm the fragmentation pathway for a series of peaks labeled $\mathrm{D}$, the complementary fragment ion $\left(31.0185 \mathrm{~m} / \mathrm{z}:\left[\mathrm{HOCH}_{2}\right]^{+}\right)$from PGA is identified in low mass portion (Figure 4a) and compared with 45.0344 $\mathrm{m} / \mathrm{z}\left(\left[\mathrm{HOCHCH}_{3}\right]^{+}\right)$from PLLA (Figure $4 \mathrm{~b}$ ). The difference $(m / z=14)$ of each complementary fragment ion corresponds to the difference $\left(\mathrm{CH}_{3}-\mathrm{H}\right)$ in mass unit according to the specific substituent at $\alpha$-position. The intensity of each ion is unique in the appropriate spectrum, and the characteristic ion is not observed where it is not expected (Figure 4). In addition, the characteristic fragment ion $\left(42.0112 \mathrm{~m} / \mathrm{z}:\left[\mathrm{CH}_{2} \mathrm{CO}\right]^{++}\right.$for PGA and $56.0264 \mathrm{~m} / \mathrm{z}:\left[\mathrm{CHCH}_{3} \mathrm{CO}\right]^{++}$for PLLA) is normally observed from each repeat unit of (Figure 4a) PGA and (Figure 4b) PLLA, respectively.

Based on the characteristic rearrangement patterns of PGA degradation products, other commercial biodegradable poly $(\alpha$-hydroxy acid)s, PLLA and PLGA, are investigated in the high $\mathrm{m} / \mathrm{z}$ region over $600 \mathrm{D}$. The

Table 2. Representative peak assignment for PGA $(\mathrm{R}=\mathrm{H})$ observed within a consecutive two most intense peaks $(*: \mathrm{n}=17 \sim 18)$

\begin{tabular}{lllr}
\hline $\mathrm{m} / \mathrm{z}$ & & \multicolumn{1}{c}{ Mass formula } & Peak assignment \\
\hline \hline$*_{17}$ & 1027 & $\mathrm{H}-[\mathrm{OCHRCO}]_{17}-\mathrm{OH}---(\mathrm{Na})^{+}$ & $*(\mathrm{G} 17)^{\mathrm{a}}$ \\
$\mathrm{A}$ & 1039 & {$[\mathrm{OCHRCO}]_{17}-\mathrm{OCHR}--(\mathrm{Na})^{+}$} & $\mathrm{A}(\mathrm{G} 18)$ \\
$\mathrm{B}$ & 1041 & $\mathrm{H}-[\mathrm{OCHRCO}]_{17}-\mathrm{OCH}{ }_{2} \mathrm{R}---(\mathrm{Na})^{+}$ & $\mathrm{B}(\mathrm{G} 18)$ \\
${ }_{17}$ & 1049 & $\mathrm{H}-[\mathrm{OCHRCO}]_{17}-\mathrm{ONa}---(\mathrm{Na})^{+}$ & $+(\mathrm{G} 17)$ \\
$\mathrm{C}$ & 1067 & $\left.[\mathrm{OCHRCO}]_{17}-\mathrm{OCHRCO}\right]_{---(\mathrm{Na})^{+}}$ & $\mathrm{C}(\mathrm{G} 18)$ \\
$\mathrm{D}$ & 1069 & $\mathrm{RCH}_{2} \mathrm{CO}-[\mathrm{OCHRCO}]_{17}-\mathrm{OH}---(\mathrm{Na})^{+}$ & $\mathrm{D}(\mathrm{G} 19)$ \\
$*_{18}$ & 1085 & $\mathrm{H}-[\mathrm{OCHRCO}]_{18}-\mathrm{OH}---(\mathrm{Na})^{+}$ & $*(\mathrm{G} 18)$ \\
\hline
\end{tabular}

${ }^{\mathrm{a}} \mathrm{G}$ and Arabic numerals in parentheses represent monomeric glycolic acid unit and the corresponding repeat numbers, respectively. 


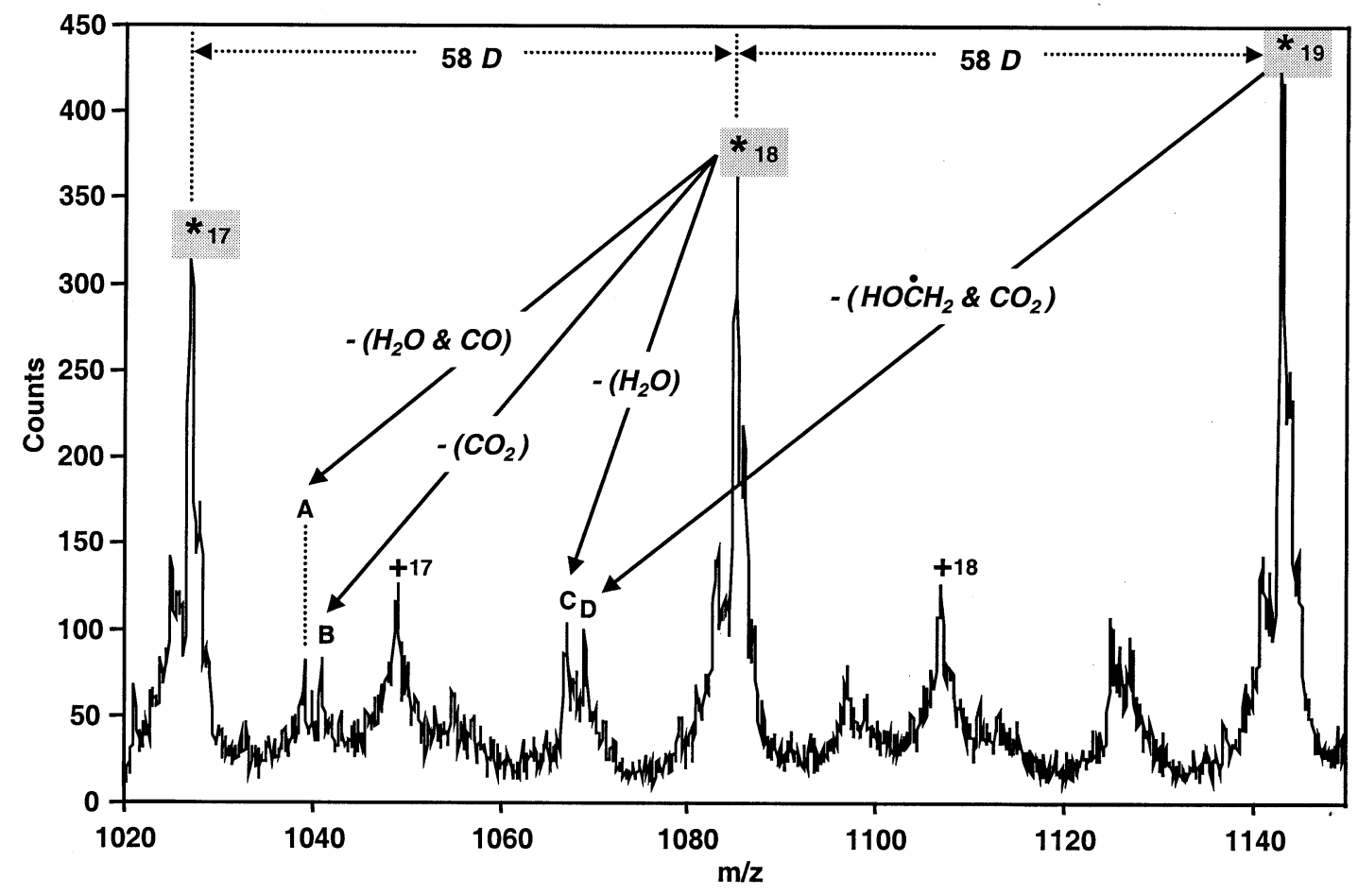

Figure 3. Possible fragmentation and neutral ion dissociation pathways of PGA degradation products adsorbed at the surface during TOF-SIMS experiment.

results from degradation treatment show that it is possible to distinguish the same family of oligomeric ion peaks. Figure $5 \mathrm{a}$ is obtained from PLLA thin films hydrolyzed in $\mathrm{pH} 10.0$ sodium carbonate buffer for $24 \mathrm{~h}$, where intact oligomeric PLLA degradation product ions $\left(\left[\mathrm{n} M_{\text {PLLA }}+\mathrm{H}_{2} \mathrm{O}+\mathrm{Na}\right]^{+}\right)$are labeled $(*)$. The
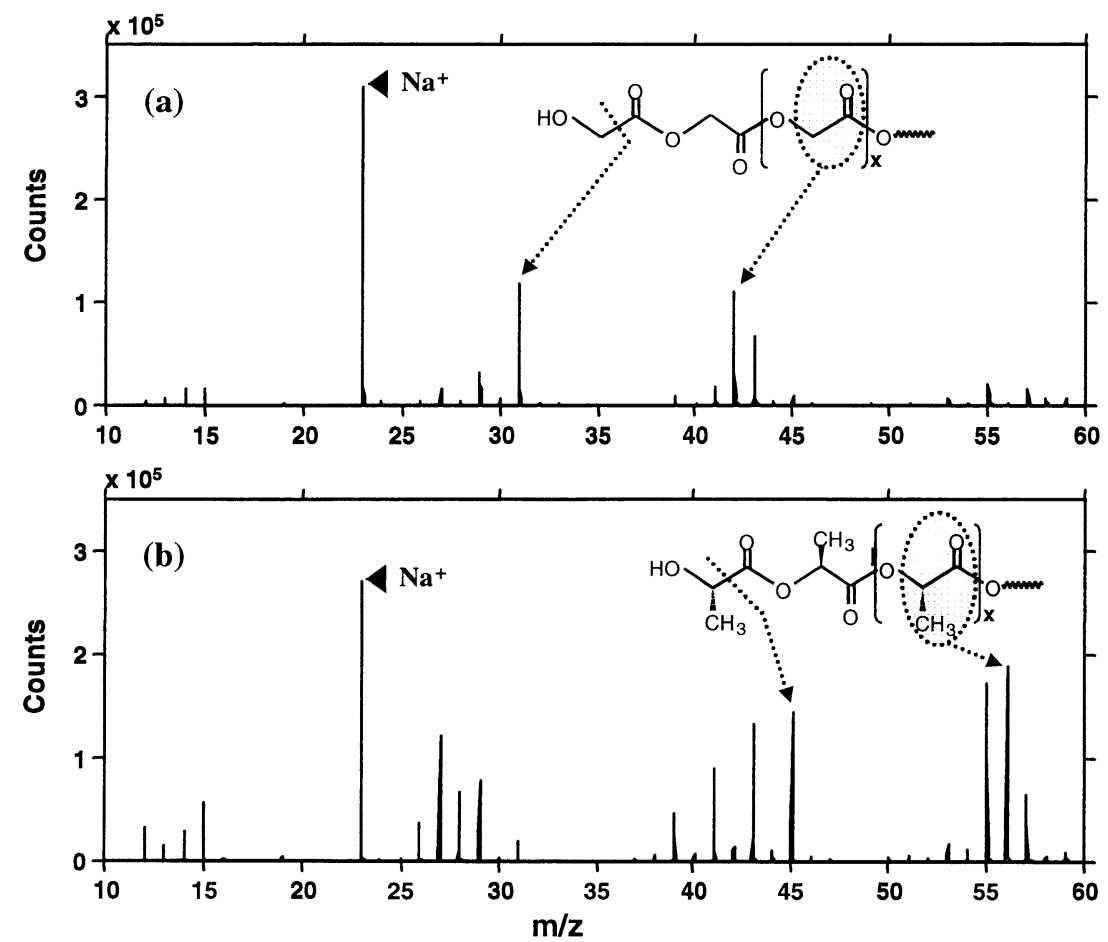

Figure 4. Characteristic fragment ions observed for (a) PGA and (b) PLLA in low $\mathrm{m} / \mathrm{z}$ range of TOF-SIMS, where PGA $100 \mu \mathrm{m}$ films have been hydrolyzed for $4 \mathrm{~h}$ and PLLA thin films for $24 \mathrm{~h}$ in $\mathrm{pH} 10.0$ sodium carbonate buffer, respectively. 


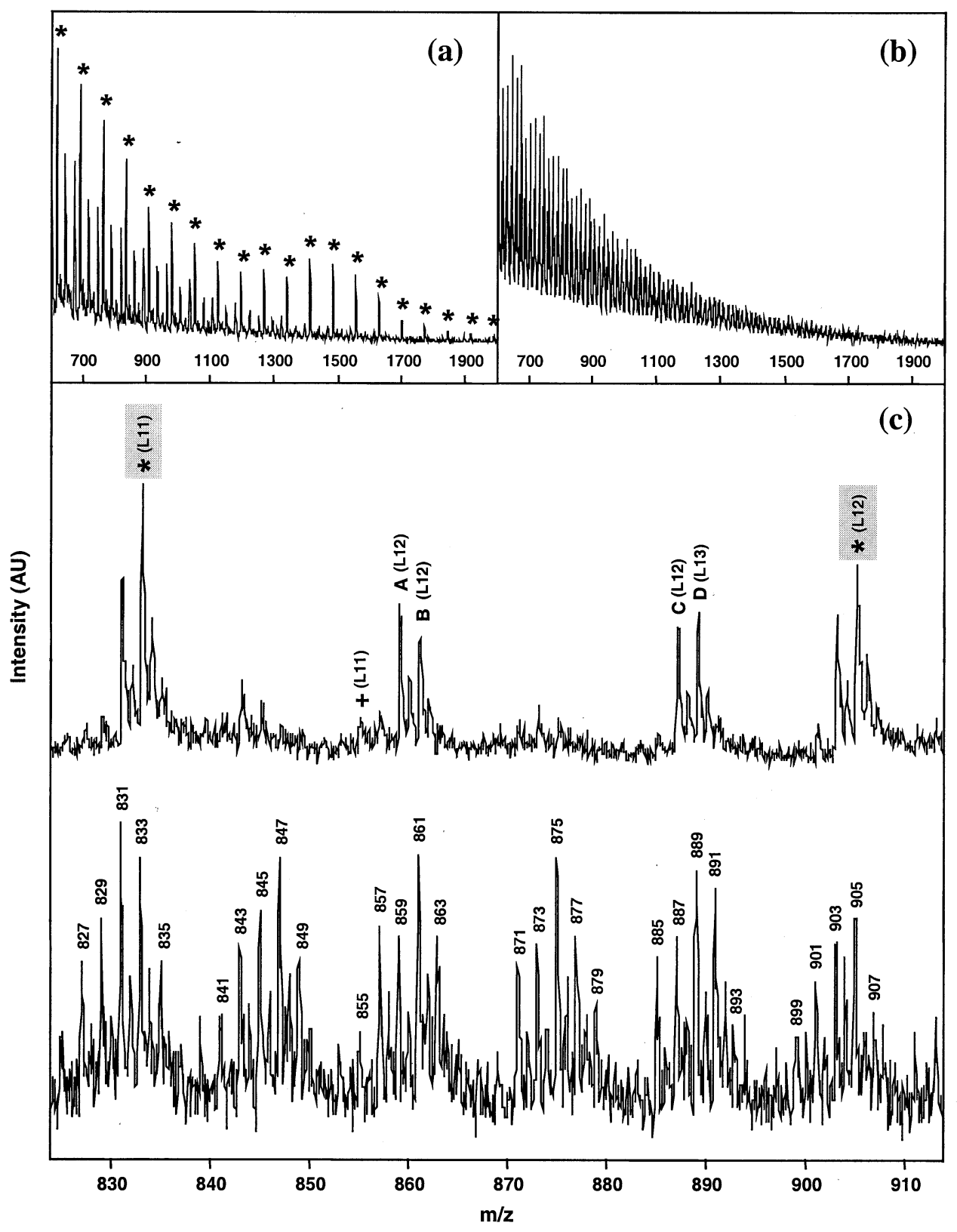

Figure 5. (a) Comparison of high mass portion of TOF-SIMS spectra of PLLA hydrolyzed in $\mathrm{pH} 10.0$ sodium carbonate buffer and (b) PLGA 50:50 copolymer hydrolyzed in pH 7.4 ISOTON II buffer for $24 \mathrm{~h}$ at $37^{\circ} \mathrm{C}$, where asterisk mark (*) represents oligomeric PLLA degradation products cationized with $\mathrm{Na}^{+},\left[\mathrm{nM}_{\mathrm{PLLA}}+\mathrm{H}_{2} \mathrm{O}+\mathrm{Na}\right]^{+}$. Bottom (c) shows peak patterns in expansion of region $\mathrm{m} / \mathrm{z}=824$ $\sim 914$ for each spectrum.

same ion formation patterns used in PGA study are applied to identify five oligomeric ion peaks, +(L11), $\mathrm{A}(\mathrm{L} 12), \mathrm{B}(\mathrm{L} 12), \mathrm{C}(\mathrm{L} 12)$, and $\mathrm{D}(\mathrm{L} 13)$, observed between the two consecutive most intense peaks, $*(\mathrm{~L} 11)$ and *(L12); they are shown at the top of Figure 5c. Figure 5b is obtained from PLGA (50:50) random copolymer films hydrolyzed in $\mathrm{pH} 7.4$ ISOTON II buffer for $24 \mathrm{~h}$. The pattern of oligomeric ion peak family is even more complicated [28] than others as seen in bottom of Figure $5 c$ due to the different degradation rates [34] of PGA and PLA segments. This complexity can be explained by the difference in hydrophobicity of each repeat unit and random chain-linkage states of each repeat unit in the backbone. However, all of the oligomeric degradation product peaks in Figure 5c (bottom) can be identified by applying the characteristic rearrangement patterns used in PGA study above. Therefore, each ion peak observed for PLLA and PLGA in the range of $\mathrm{m} / \mathrm{z}$ $825 \sim 915$ is distinguished in Table 3, where the intact PLGA hydrolysis product ions $(*$ and + ) are collected in the highlighted section. Subscripts ${ }_{\mathrm{G}}$ and $\mathrm{L}_{\mathrm{L}}$ in the peaks assignment of PLGA fragments represent end groups 
Table 3. Ions observed for PLLA and PLGA in the range of $m / z$ 825 915

\begin{tabular}{|c|c|c|c|}
\hline \multirow[b]{2}{*}{$m / z$} & \multicolumn{3}{|r|}{ Peak assignment } \\
\hline & PPLA & & PLGA \\
\hline 827 & & $+(\mathrm{L} 9 / \mathrm{G} 2)^{\mathrm{a}}$ & \\
\hline 829 & & $+(\mathrm{L} 5 / \mathrm{G} 7)$ & \\
\hline 831 & & $+(\mathrm{L} 1 / \mathrm{G} 12)$ & $A_{G}(L 10 / G 2), A_{L}(L 10 / G 2), C_{G}(L 8 / G 4), C_{L}(L 8 / G 4)^{b}$ \\
\hline 833 & $*(\mathrm{~L} 11)$ & $*(\mathrm{~L} 11)$ & $\begin{array}{l}A_{G}(L 6 / G 7), A_{L}(L 6 / G 7), B_{G}(L 10 / G 2), B_{L}(L 10 / G 2), C_{G}(L 4 / G 9), C_{L}(L 4 / G 9) \\
D_{G}(L 9 / G 4), D_{L}(L 9 / G 4), D_{G}(L 8 / G 5), D_{L}(L 8 / G 5)\end{array}$ \\
\hline 835 & & $*(\mathrm{~L} 7 / \mathrm{G} 5)$ & $\begin{array}{l}A_{G}(L 2 / G 12), A_{L}(L 2 / G 12), B_{G}(L 6 / G 7), B_{L}(L 6 / G 7), C_{G}(G 14) \\
D_{G}(L 5 / G 9), D_{L}(L 5 / G 9), D_{G}(L 4 / G 10), D_{L}(L 4 / G 10)\end{array}$ \\
\hline 841 & & $+(\mathrm{L} 10 / \mathrm{G} 1)$ & \\
\hline 843 & & $+(\mathrm{L} 6 / \mathrm{G} 6)$ & \\
\hline 845 & & $+(\mathrm{L} 2 / \mathrm{G} 11)$ & $A_{G}(L 11 / G 1), A_{L}(L 11 / G 1), C_{G}(L 9 / G 3), C_{L}(L 9 / G 3)$ \\
\hline 847 & & & $\begin{array}{l}A_{G}(L 7 / G 6), A_{L}(L 7 / G 6), B_{G}(L 11 / G 1), B_{L}(L 11 / G 1), C_{G}(L 5 / G 8), C_{L}(L 5 / G 8) \\
D_{G}(L 10 / G 3), D_{L}(L 10 / G 3), D_{G}(L 9 / G 4), D_{L}(L 9 / G 4)\end{array}$ \\
\hline 849 & & $*(\mathrm{~L} 8 / \mathrm{G} 4)$ & $\begin{array}{l}A_{G}(L 3 / G 11), A_{L}(L 3 / G 11), B_{G}(L 7 / G 6), B_{L}(L 7 / G 6), C_{G}(L 1 / G 13), C_{L}(L 1 / G 13) \\
D_{G}(L 6 / G 8), D_{L}(L 6 / G 8), D_{G}(L 5 / G 9), D_{L}(L 5 / G 9)\end{array}$ \\
\hline 855 & $+(\mathrm{L} 11)$ & $+(\mathrm{L} 11)$ & \\
\hline 857 & & $+(\mathrm{L} 7 / \mathrm{G} 5)$ & \\
\hline 859 & $A(L 12)$ & $+(\mathrm{L} 3 / \mathrm{G} 10)$ & $A_{L}(L 12), C_{G}(L 10 / G 2), C_{L}(L 10 / G 2)$ \\
\hline 861 & $B(L 12)$ & & $\begin{array}{l}A_{G}(L 8 / G 5), A_{L}(L 8 / G 5), B_{L}(L 12), C_{G}(L 6 / G 7), C_{L}(L 6 / G 7) \\
D_{G}(L 11 / G 2), D_{L}(L 11 / G 2), D_{G}(L 10 / G 3), D_{L}(L 10 / G 3)\end{array}$ \\
\hline 863 & & $*(\mathrm{~L} / \mathrm{G} 3)$ & $\begin{array}{l}A_{G}(L 4 / G 10), A_{L}(L 4 / G 10), B_{G}(L 8 / G 5), B_{L}(L 8 / G 5), C_{G}(L 2 / G 12), C_{L}(L 2 / G 12) \\
D_{G}(L 7 / G 7), D_{L}(L 7 / G 7), D_{G}(L 6 / G 8), D_{L}(L 6 / G 8)\end{array}$ \\
\hline 871 & & $+(\mathrm{L} 8 / \mathrm{G} 4)$ & \\
\hline 873 & & $+(\mathrm{L} 4 / \mathrm{G} 9)$ & $C_{G}(L 11 / G 1), C_{L}(L 11 / G 1)$ \\
\hline 875 & & $+(\mathrm{G} 14)$ & $\begin{array}{l}A_{G}(L 9 / G 4), A_{L}(L 9 / G 4), C_{G}(L 7 / G 6), C_{L}(L 7 / G 6) \\
D_{L}(L 12 / G 1), D_{G}(L 11 / G 2), D_{L}(L 11 / G 2)\end{array}$ \\
\hline 877 & & $*(\mathrm{~L} 10 / \mathrm{G} 2)$ & $\begin{array}{l}A_{G}(L 5 / G 9), A_{L}(L 5 / G 9), B_{G}(L 9 / G 4), B_{L}(L 9 / G 4), C_{G}(L 3 / G 11), C_{L}(L 3 / G 11) \\
D_{G}(L 8 / G 6), D_{L}(L 8 / G 6), D_{G}(L 7 / G 7), D_{L}(L 7 / G 7)\end{array}$ \\
\hline 879 & & $*($ L6/G7) & $\begin{array}{l}A_{G}(L 1 / G 14), A_{L}(L 1 / G 14), B_{G}(L 5 / G 9), B_{L}(L 5 / G 9) \\
D_{G}(L 4 / G 11), D_{L}(L 4 / G 11), D_{G}(L 3 / G 12), D_{L}(L 3 / G 12)\end{array}$ \\
\hline 885 & & $+(\mathrm{L} 9 / \mathrm{G} 3)$ & \\
\hline 887 & $C(L 12)$ & $+(\mathrm{L} 5 / \mathrm{G} 8)$ & $C_{L}(L 12)$ \\
\hline 889 & $\mathrm{D}(\mathrm{L} 13)$ & $+(\mathrm{L} 1 / \mathrm{G} 13)$ & $A_{G}(L 10 / G 3), A_{L}(L 10 / G 3), C_{G}(L 8 / G 5), C_{L}(L 8 / G 5), D_{L}(L 13), D_{L}(L 12 / G 1)$ \\
\hline 891 & & $*(\mathrm{~L} 11 / \mathrm{G} 1)$ & $\begin{array}{l}A_{G}(L 6 / G 8), A_{L}(L 6 / G 8), B_{G}(L 10 / G 3), B_{L}(L 10 / G 3), C_{G}(L 4 / G 10), C_{L}(L 4 / G 10) \\
D_{G}(L 9 / G 5), D_{L}(L 9 / G 5), D_{G}(L 8 / G 6), D_{L}(L 8 / G 6)\end{array}$ \\
\hline 893 & & $*(\mathrm{~L} 7 / \mathrm{G} 6)$ & $A_{G}(L 2 / G 13), A_{L}(L 2 / G 13), B_{G}(L 6 / G 8), B_{L}(L 6 / G 8), C_{G}(G 15)$ \\
\hline 899 & & $+(\mathrm{L} 10 / \mathrm{G} 2)$ & \\
\hline 901 & & $+(\mathrm{L} 6 / \mathrm{G} 7)$ & \\
\hline 903 & & $+(\mathrm{L} 2 / \mathrm{G} 12)$ & $A_{G}(L 11 / G 2), A_{L}(L 11 / G 2), C_{G}(L 9 / G 4), C_{L}(L 9 / G 4)$ \\
\hline 905 & $*(\mathrm{~L} 12)$ & $*(\mathrm{~L} 12)$ & $\begin{array}{l}A_{G}(L 7 / G 7), A_{L}(L 7 / G 7), B_{G}(L 11 / G 2), B_{L}(L 11 / G 2), C_{G}(L 5 / G 9), C_{L}(L 5 / G 9) \\
D_{G}(L 10 / G 4), D_{L}(L 10 / G 4), D_{G}(L 9 / G 5), D_{L}(L 9 / G 5)\end{array}$ \\
\hline 907 & & $*(\mathrm{~L} 8 / \mathrm{G} 5)$ & $A_{G}(L 3 / G 12), A_{L}(L 3 / G 12), B_{G}(L 7 / G 7), B_{L}(L 7 / G 7), C_{G}(L 1 / G 14), C_{L}(L 1 / G 14)$ \\
\hline
\end{tabular}

aHighlighted section indicates intact hydrolytic degradation products cationized with $\mathrm{Na}^{+}$at the surface of PLGA.

${ }^{\text {bSubscript }} G$ and $L$ represent end groups rearranged from glycolic $(G)$ and lactic $(L)$ acid structure, respectively.

rearranged from glycolic $(\mathrm{G})$ and lactic (L) acid structure, respectively as shown in the mass formula of Table 2. In counting representative peak assignments, the full range of possibilities are considered for combination and/or permutation of each repeat unit based on the PLGA structure being expected from ring-opening polymerization (ROP) [35] of glycolide (cyclic diester of glycolic acid) and lactide (cyclic diester of lactic acid). For example, the $\mathrm{C}_{\mathrm{G}}(\mathrm{L} 12 / \mathrm{G} 1)$ peak assignment for 875 $\mathrm{m} / \mathrm{z}$ is excluded in Table 3 since the formation of $\mathrm{H}-M_{\mathrm{PLA}}-M_{\mathrm{PGA}}-\left[M_{\mathrm{PLA}}\right]_{11}-\mathrm{OH}$ in possible chemical structures for $*(\mathrm{~L} 12 / \mathrm{G} 1)$ is impossible when considering both ROP of cyclic diesters and hydrolytic degradation of polymer chain linkages. The intensities of oligomeric PLGA fragments are greater than those of intact degra- dation products, as seen in bottom of Figure 5c. This is because the oligomeric fragments originated from various kinds of intact degradation products with greater mass can contribute to the peak intensity at a particular $m / z$.

In an attempt to extract MW average from the degradation-generated oligomeric PGA distribution developed at the surface, each intensity of six ion peak family $[*(\mathrm{Gn}), \mathrm{A}(\mathrm{Gn}), \mathrm{B}(\mathrm{Gn}),+(\mathrm{Gn}), \mathrm{C}(\mathrm{Gn})$, and $\mathrm{D}(\mathrm{Gn})]$ with the same repeat number (n) is integrated and summed as the total intensity $\left(N_{\mathrm{i}}, \mathrm{i}=\mathrm{n}\right)$ for the particular degradation product, $*(\mathrm{Gn}): M_{\mathrm{i}}=\mathrm{n} \times M_{\mathrm{PGA}}$ $+\mathrm{H}_{2} \mathrm{O}$, over the range from $600 \mathrm{D}$ to the last detectable peak in all data analyses. This represents two changes from our previous quantification practice [27, 29]: (1) 
Table 4. Effect of data reduction methods on quantitative TOF-SIMS results for PGA degradation products adsorbed at the surface during hydrolysis treatment in $\mathrm{pH} 7.4$ buffer for 3 hours

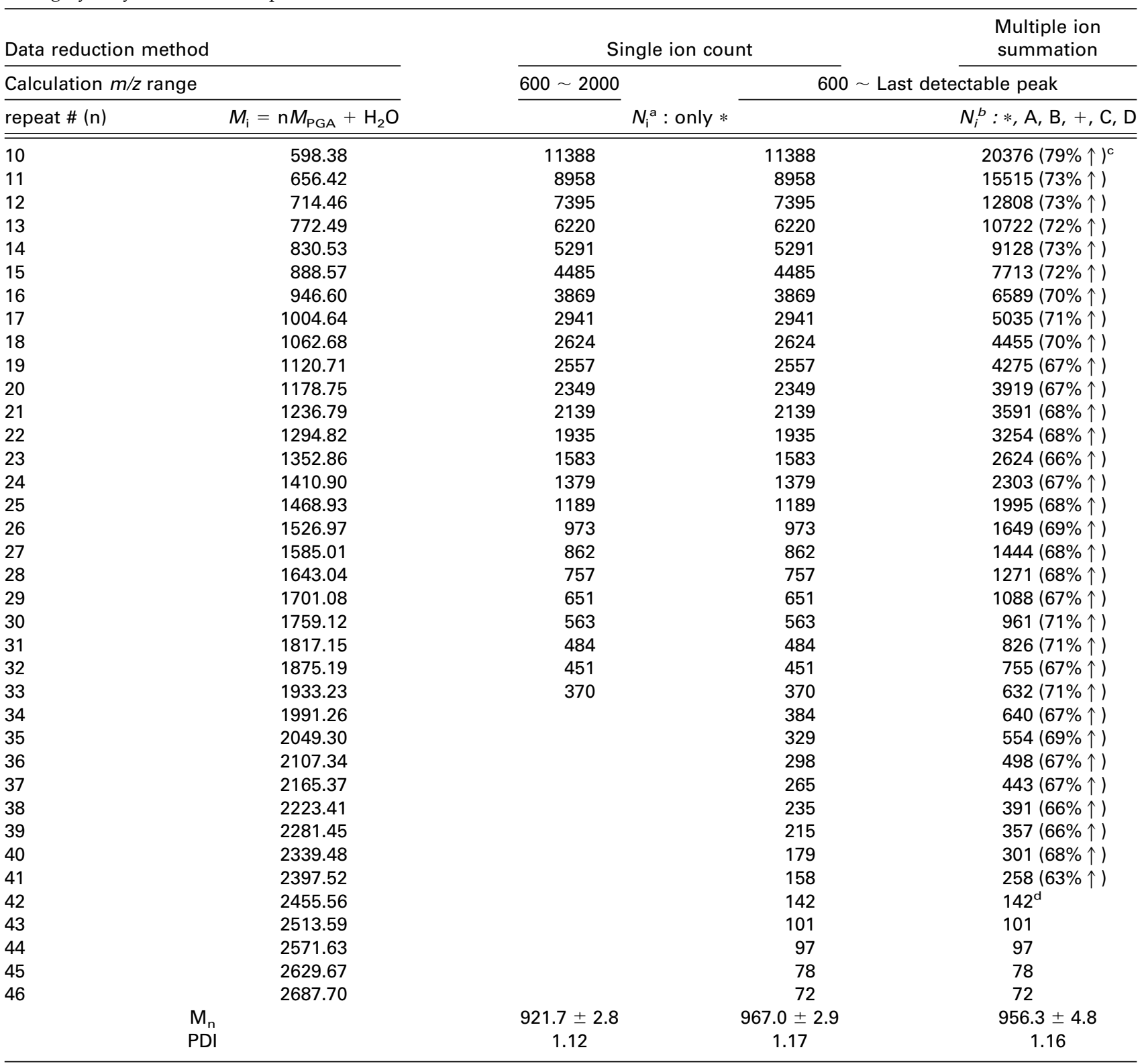

${ }^{\mathrm{a}}$ and ${ }^{\mathrm{b}}$ Average intensities obtained within $0.3 \%$ and $0.5 \%$ relative deviation, respectively.

${ }^{c}$ The percentages for intensity increases after multiple ion counts are given in parentheses.

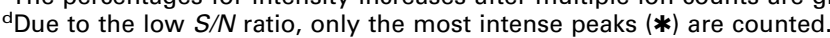

only the most intense degradation ion peak, *(Gn), was counted as a representative intensity and (2) only a fixed $\mathrm{m} / \mathrm{z}$ range (i.e., $600 \sim 2000 \mathrm{D}$ ) was chosen in all data analyses for the quantification of MWD. It is postulated that the accuracy in data reduction would be improved by counting each oligomeric ion peak family with the same $\mathrm{n}$ rather than only the most intense ion peak if all of each would be attributed from the intact degradation products. Two observations support this proposal: (1) Figure 1c shows the alkali metal substrate effects on the cationization process ( $*$ and v) and (2) Figure $2 \mathrm{a}$ shows the change in relative intensities of two series of intact degradation products $(*$ and +$)$. Further- more, most of oligomeric ion peaks in TOF-SIMS are detectable beyond $2000 \mathrm{D}$ with the increase in hydrolysis time within the induction period $[26,36]$. The effect of data reduction methods on MW average extracted from MWD is given in Table 4. Single ion count in the fixed $m / z$ range (i.e., $600 \sim 2000$ D) indicates the previous method [29] and multiple ion summation for six ion peak family $(*, A, B,+, C$, and D) represents the proposed method in this paper. The total intensities in multiple ion summation method are increased by over $60 \%$ up to $80 \%$ compared to those measured in the single ion count method and the relative contribution to the total intensities decreases with increasing $m / z$ of the 
Table 5. Comparison of MW averages and hydrolytic degradation kinetics at the surface of PGA calculated from each data reduction method

\begin{tabular}{|c|c|c|c|c|c|c|c|}
\hline \multicolumn{2}{|c|}{ Data reduction method } & \multicolumn{3}{|c|}{ Multiple ion summation } & \multicolumn{3}{|c|}{ Single ion count } \\
\hline \multicolumn{2}{|c|}{ Calculation $\mathrm{m} / \mathrm{z}$ range } & \multicolumn{3}{|c|}{$600 \sim$} & \multicolumn{3}{|c|}{$600 \sim 2000$} \\
\hline \multicolumn{2}{|c|}{ Hydrolysis condition } & \multicolumn{6}{|c|}{ Physiological buffer : ISOTON ${ }^{\circledR}$ II (pH 7.4) } \\
\hline \multirow{6}{*}{$\begin{array}{l}\text { Hydrolysis } \\
\text { condition }\end{array}$} & Time (h) & $M_{\mathrm{n}}$ & PDI & DP & $M_{\mathrm{n}}$ & PDI & DP \\
\hline & 1 & $877.1 \pm 4.4$ & 1.11 & 14.8 & $849.8 \pm 2.5$ & 1.08 & 14.3 \\
\hline & 2 & $929.2 \pm 4.6$ & 1.14 & 15.7 & $899.6 \pm 2.7$ & 1.11 & 15.2 \\
\hline & 3 & $956.3 \pm 4.8$ & 1.16 & 16.2 & $921.7 \pm 2.8$ & 1.12 & 15.6 \\
\hline & 4 & $952.2 \pm 4.8$ & 1.16 & 16.1 & $919.0 \pm 2.8$ & 1.12 & 15.5 \\
\hline & 6 & $944.9 \pm 4.7$ & 1.14 & 16.0 & $912.2 \pm 2.7$ & 1.11 & 15.4 \\
\hline Degradation & $k\left(\mathrm{hr}^{-1}\right)$ & \multicolumn{3}{|c|}{$2.67 \mathrm{E}-4$} & \multicolumn{3}{|c|}{$2.46 \mathrm{E}-4$} \\
\hline kinetics & $\mathrm{R}^{2}$ & \multicolumn{3}{|c|}{0.999} & \multicolumn{3}{|c|}{0.997} \\
\hline
\end{tabular}

spectrum. As a reference, the result of single ion count over the $\mathrm{m} / \mathrm{z}$ range up to last detectable peak is compared with both methods. MW averages and PDI are increased $\left(M_{\mathrm{n}}: 921 \rightarrow 967\right.$, PDI: $\left.1.12 \rightarrow 1.17\right)$ due to the contribution of higher mass peaks detected beyond 2000 D. By counting the contribution of oliogmeric fragments (A, B, C, and D) and the other degradationgenerated intact hydrolysis product $(+)$ to the total intensity for the particular intact degradation product $(*)$, however, the accuracy of quantitative TOF-SIMS is adjusted with the practical value $\left(M_{\mathrm{n}}: 967 \rightarrow 956\right.$, PDI: $1.17 \rightarrow 1.16$ ).

Table 5 shows MW averages and hydrolytic surface degradation kinetics calculated from each quantitative data reduction method for the degradation products generated at the surface during the induction period of PGA bulk erosion profile in $\mathrm{pH}$ 7.4 physiological buffer condition. The comparison of (Figure 6a) extent of changes in $M_{\mathrm{n}}$ and (Figure $6 \mathrm{~b}$ ) hydrolytic degradation kinetics for multiple ion counts versus single ion count practices is plotted in Figure 6 as a function of hydrolysis time with the same scale. As expected, PDIs in the fixed $m / z$ range $(600 \sim 2000 \mathrm{D})$ are closer to 1 than those calculated in the present study. A significant change is observed in the plots of $M_{\mathrm{n}} \mathrm{s}$; each MW average in the multiple ion summation shows a greater value than the corresponding one obtained from the single ion count in the fixed $\mathrm{m} / \mathrm{z}$ range. This improvement can be possible by counting together degradation-generated intact hydrolysis products $(*$ and + ) and their fragments $(\mathrm{A}$, $B, C$, and D). The detail surface characteristics for initial increase followed by decrease in $M_{n}$ has been extensively studied in the recent paper [30]. From 3-h hydrolysis time showing $M_{\mathrm{n}}$ decreases, the kinetics study of

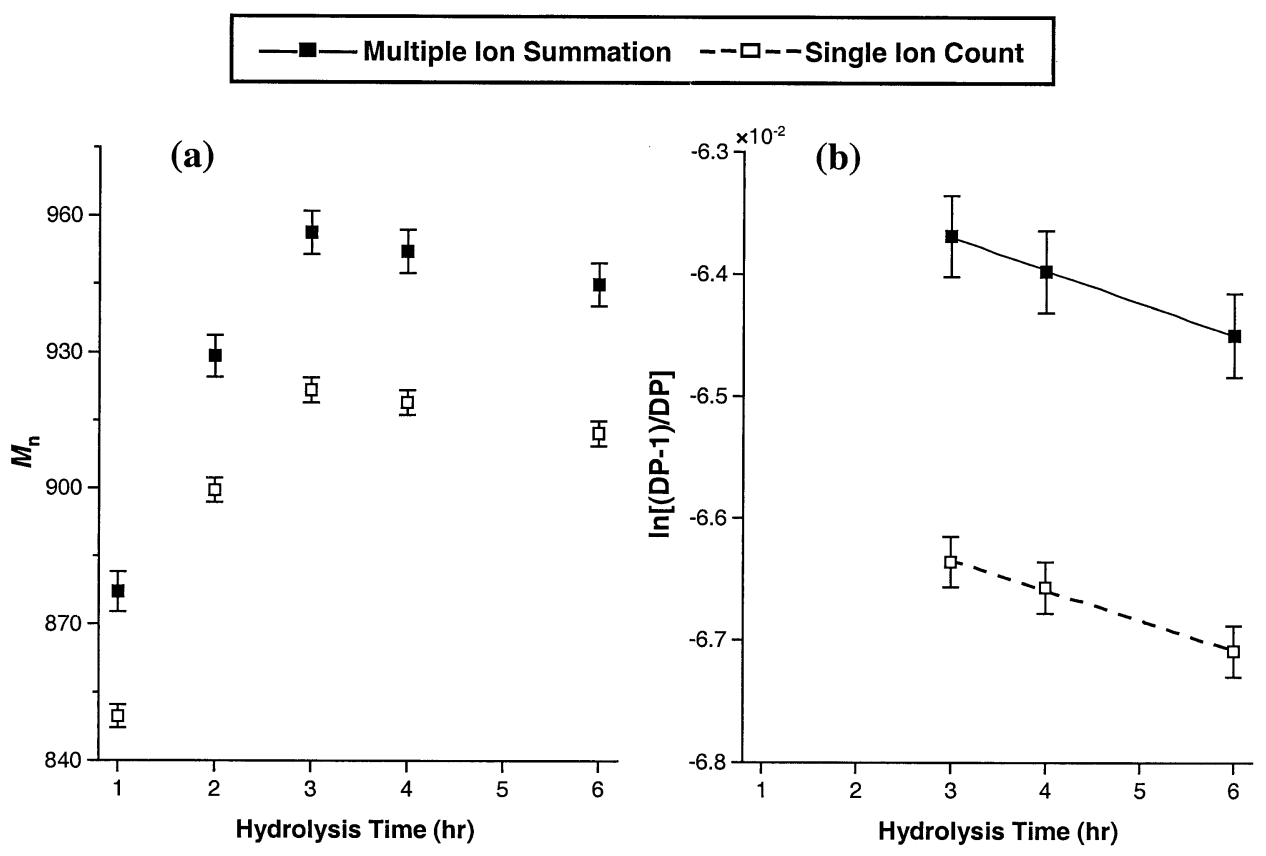

Figure 6. Quantitative TOF-SIMS results depending on data reduction methods: (a) Extent of changes in $M_{\mathrm{n}} ;(\mathbf{b})$ hydrolytic degradation kinetics. 
the hydrolytic surface degradation can be established. The kinetic expression, Eq 4, is applied for non-catalytic chain scission mechanism $[25,29]$ in $\mathrm{pH} 7.4$ ISOTON II buffered condition. In both data reduction practices, good linearity can be obtained from the data and rate constants can be calculated from the slope showing the decrease in linear relationship. However, little significance is observed in the final kinetics results. This is because a rate constant in the present kinetics study reflects mathematical meaning for relative decrease trend in a given series of data, not based on absolute data.

\section{Conclusion}

The accuracy of MW averages extracted from TOFSIMS MWD is improved in the hydrolytic degradation studies of a series of biodegradable $\operatorname{poly}(\alpha-$ hydroxy acid)s (i.e., PGA, PLLA, and PLGA). This can be possible by counting together a family of degradation-generated intact molecular ions and their corresponding fragment ions as a representative intensity $\left(N_{\mathrm{i}}\right)$ for the particular intact degradation product $\left(M_{\mathrm{i}}=\mathrm{n} \times M_{\text {mon }}+\mathrm{H}_{2} \mathrm{O}\right.$, where $\left.\mathrm{i}=\mathrm{n}\right)$. The present multiple ion summation method leads to a better data reduction for MW average information than the single ion count only analyzing the most intense degradation products.

Oligomeric intact degradation products and their fragments in positive TOF-SIMS spectra of a series of poly( $\alpha$-hydroxy acid)s hydrolyzed in various buffered conditions have been distinguished by their $m / z$ values and peak intensity patterns. The intensities of intact degradation product ion peak show typical distribution curves, while the intensities of fragment ion peaks decrease as $m / z$ increases. Degradation-generated oligomeric molecular ion peaks are identified as the intact hydrolysis products adsorbed at the surface and their desorption probability is greater than the fragmentation occurring during TOF-SIMS experiment.

Oligomeric fragment ion peaks are consistently observed in the same series of consecutive intact degradation product ion peaks. They show the periodic peak spacings corresponding to each polymer repeat unit $\left(M_{\mathrm{PGA}}, M_{\mathrm{PLLA}}\right)$, which facilitate the spectral interpretation for degradation products adsorbed at the surface of poly( $\alpha$-hydroxy acid)s. Each fragment ion peaks can be identified by the unique rearrangement via fragmentation and neutral ion dissociation pathways occurring at both end groups of intact degradation products during TOF-SIMS experiment.

The present work is intended to provide an approach for better data reduction in quantitative TOF-SIMS that will have considerable value for surface analysis of biodegradable polymers as a function of hydrolysis treatment.

\section{Acknowledgments}

The authors acknowledge support from the National Science Foundation Analytical and Surface Chemistry program, grants CHE 9704996 and 0079114 . They are grateful for critical review of the manuscript by Professor Troy D. Wood, Department of Chemistry, SUNY at Buffalo and generous donation of PGA from Dr. Peter Jarrett, American Cyanamid Corporation.

\section{References}

1. Olefjord, I.; Nyborg, L.; Briggs, D. Proceedings of 7th European Conference on Applications of Surface and Interface Analysis; John Wiley \& Sons: Chichester, 1997.

2. Briggs, D. In Surface Analysis of Polymers by XPS and Static SIMS, Clarke D. R.; Suresh S.; Ward, I. M., Eds.; Cambridge University Press: Cambridge, 1998.

3. Vickerman, J. C.; Leggett, G. J.; Hagenhoff, B.; Briggs, D.; Chilkoti, A.; Bryan, S. R.; McKeown, P. J. In Static SIMS Library; Surface Spectra: Manchester, 1998.

4. Bertrand, P.; Weng, L. T. In Surface Characterization: A Practical Approach; VCH Publishers: New York, 1997.

5. Nowak, R. W.; Gardella, J. A., Jr.; Wood, T. D.; Zimmerman, P. A.; Hercules, D. M. Interchain Ion Formation in Secondary Ion Mass Spectrometry Resulting from the Double-Helical Structure of Isotactic Poly(methyl methacrylate) in Adsorbed Monolayers. Anal. Chem. 2000, 72, 4585-4590.

6. Galuska, A. A. Quantitative Surface Analysis of EthylenePropylene Polymers using TOF-SIMS. Surf. Interface Anal. 1997, 25, 1-4.

7. Chen, X.; Gardella, J. A., Jr.; Ho, T.; Wynne, K. J. Surface Composition of a Series of Dimethylsiloxane Urea, Urethane Segmented Copolymers Studied by Electron Spectroscopy for Chemical Analysis. Macromolecules 1995, 28, 1635-1642.

8. Gardella, J. A., Jr.; Hercules, D. M. Static Secondary Ion Mass Spectrometry (SIMS) of Polymer Systems. Anal. Chem. 1980, 52, 226-232.

9. Reichlmaier, S.; Bryan, S. R.; Briggs, D. Surface Trimer Crystallization on Poly(ethylene terephthalate) Studied by Timeof-Flight Secondary Ion Mass Spectrometry. J. Vac. Sci. Technol. A 1995, 13, 1217-1223.

10. Lin, L.; Chan, C.-M.; Weng, L.-T.; Xiang, M.-L.; Jiang, M. Specific Interaction between Poly(styrene-co-4-vinylphenol) and Poly(styrene-co-4-vinylpyridine) Studied by X-ray Photoelectron Spectroscopy and Time-of-Flight Secondary Ion Mass Spectrometry. Macromolecules 1998, 31, 7248-7255.

11. Bletsos, I. V.; Hercules, D. M.; Magill, J. H.; van Leyen, D.; Niehuis, E.; Benninghoven, A. Time-of-Flight Secondary Ion Mass Spectrometry: Detection of Fragments from Thick Polymer Films in the Range $m / z \leq 4500$. Anal. Chem. 1988, 60, 938-944.

12. Lub, J.; van Vroonhoven, D.; van Leyen, D.; Benninghoven, A. Static Secondary Ion Mass Spectrometry Analysis of Polycarbonate Surfaces. Effect of Structure and of Surface Modification on the Spectra. Polymer 1988, 29, 998-1003.

13. Lub, J.; van Velzen, P. N. T.; van Leyen, D.; Hagenhoff, B.; Benninghoven, A. TOF-SIMS Analysis of the Surface of Insulators. Examples of Chemically Modified Polymers and Glass. Surf. Interface Anal. 1988, 12, 53-57.

14. Bletsos, I. V.; Hercules, D. M.; van Leyen, D.; Benninghoven, A.; Karakatsanis, C. G.; Rieck, J. N. Structural Characterization of Model Polyurethanes using Time-of-Flight Secondary Ion Mass Spectrometry. Anal. Chem. 1989, 61, 2142-2149.

15. Bletsos, I. V.; Hercules, D. M.; van Leyen, D.; Benninghoven, A.; Fowler, D. Time-of-Flight Secondary Ion Mass Spectrometry of Perfluorinated Polyethers. Anal. Chem. 1990, 62, 1275-1284. 
16. Briggs, D.; Davies, M. C. Analysis of Polymer Surfaces by SIMS: Part 21. Quantitative Study of Methyl MethacrylatePoly(ethylene glycol) Methacrylate Copolymer Films using High Mass Resolution TOF-SIMS. Surf. Interface Anal. 1997, 25, 725-733.

17. Galuska, A. A. Surface Characterization of EMA Copolymers using XPS and TOF-SIMS. Surf. Interface Anal. 1996, 24, 380-388.

18. Elman, J. F.; Lee, D. H.-T.; Koberstein, J. T.; Thompson, P. M. Time-of-Flight Secondary Ion Mass Spectrometric Measurements of Molecular Weight Distributions for Functionally Terminated Oligomers and Transferred Langmuir-BlodgettKuhn Monolayers. Langmuir 1995, 11, 2761-2767.

19. Bletsos, I. V.; Hercules, D. M.; van Leyen, D.; Hagenhoff, B.; Niehuis, E.; Benninghoven, A. Molecular Weight Distributions of Polymers using Time-of-Flight Secondary Ion Mass Spectrometry. Anal. Chem. 1991, 63, 1953-1960.

20. Bletsos, I. V.; Hercules, D. M.; van Leyen, D.; Benninghoven, A. Time-of-Flight Secondary Ion Mass Spectrometry of Polymers in the Mass Range 500-10,000. Macromolecules 1987, 20, 407-413.

21. Yan, W.; Ammon, D. M., Jr.; Gardella, J. A., Jr.; Maziarz, E. P., III; Hawkridge, A. M.; Grobe, G. L., III; Wood, T. D. Quantitative Mass Spectrometry of Technical Polymers: A Comparison of Several Ionization Methods. Eur. Mass Spectrom. 1998, 4, 467-474.

22. Parees, D. M.; Hanton, S. D.; Cornelio Clark, P. A.; Wilcox, D. A. Comparison of Mass Spectrometric Techniques for Generating Molecular Weight Information on a Class of Ethoxylated Oligomers. J. Am. Soc. Mass Spectrom. 1998, 9, 282-291.

23. Park, T. G. Degradation of Poly(lactic-co-glycolic acid) Microspheres: Effect of Copolymer Composition. Biomaterials 1995, 16, 1123-1130.

24. Park, T. G.; Cohen, S.; Langer, R. Poly(L-lactic acid)/Pluronic Blends: Characterization of Phase Separation Behavior, Degradation, and Morphology and Use as Protein-Releasing Matrixes. Macromolecules 1992, 25, 116-122.

25. Zhu, K. J.; Hendren, R. W.; Jensen, K.; Pitt, C. G. Synthesis, Properties, and Biodegradation of Poly(1,3-trimethylene carbonate). Macromolecules 1991, 24, 1736-1740.
26. Kenley, R. A.; Lee, M. O.; Mahoney, R., II; Sanders, L. M. Poly(lactide-co-glycolide) Decomposition Kinetics in Vivo and in Vitro. Macromolecules 1987, 20, 2398-2403.

27. Gardella, J. A., Jr.; Hernandez de Gatica, N. L. The Determination of Structure and Reactivity at the Surfaces of Materials used in Biology: Needs and Requirements for Electron and Ion Spectroscopy for Surface Analysis. J. Electron Spectrosc. Relat. Phenom. 1996, 81, 227-236.

28. Chen, J.; Gardella, J. A., Jr. Time of Flight Secondary Ion Mass Spectrometry Studies of in Vitro Hydrolytic Degradation of Biodegradable Polymers. Macromolecules 1999, 32, 7380-7388.

29. Chen, J.; Lee, J.-W.; Hernandez de Gatica, N. L.; Burkhardt, C. A.; Hercules, D. M.; Gardella, J. A., Jr. Time-of-Flight Secondary Ion Mass Spectrometry Studies of Hydrolytic Degradation Kinetics at the Surface of Poly(glycolic acid). Macromolecules 2000, 33, 4726-4732.

30. Lee, J.-W.; Gardella, J. A., Jr. In Vitro Hydrolytic Surface Degradation of Poly(glycolic acid): Role of the Surface Segregated Amorphous Region in the Induction Period of Bulk Erosion. Macromolecules 2001, 34, 3928-3937.

31. Therin, M.; Christel, P.; Li, S. M.; Garreau, H.; Vert, M. In Vivo Degradation of Massive Poly(hydroxy acids): Validation of in Vitro Findings. Biomaterials 1992, 13, 594-600.

32. Li, S. M.; Garreau, H.; Vert, M. Structure-Property Relationships in the Case of the Degradation of Massive Poly(hydroxy acids) in Aqueous Media. Part 1. Poly(D,L-lactic acid). J. Mater. Sci. Mater. Med. 1990, 1, 123-130.

33. Googly Software, Copyright 1994 Andrew Proctor.

34. Reed, A. M.; Gilding, D. K. Biodegradable Polymers for Use in Surgery: Poly(glycolic)/Poly(lactic acid) Homo- and Copolymers. 2. In Vitro Degradation. Polymer 1981, 22, 494-498.

35. Gilding, D. K.; Reed, A. M. Biodegradable Polymers for Use in Surgery. Polyglycolic/Poly(lactic acid) Homo- and Copolymers: 1. Polymer 1979, 20, 1459-1464.

36. Pitt, C. G.; Gratzel, M. M.; Kimmel, G. L.; Surles, J.; Schindler, A. Aliphatic Polyesters. II. The Degradation of Poly(DLlactide), Poly( $\varepsilon$-caprolactone), and their Copolymers in Vivo. Biomaterials 1981, 2, 215-220. 